\title{
Abusive Supervision and Counterproductive Work Behavior: Moderating Effect of Negative Affectivity
}

\author{
Feng An, Bing Wang \\ School of Business Administration, University of Science \& Technology Liaoning, Anshan, China \\ Email: af218@126.com, liaoningkdwb@163.com
}

Received 30 December 2015; accepted 14 February 2016; published 17 February 2016

Copyright $@ 2016$ by authors and Scientific Research Publishing Inc.

This work is licensed under the Creative Commons Attribution International License (CC BY). http://creativecommons.org/licenses/by/4.0/

c) (i) Open Access

\begin{abstract}
In this study, the methods of literature study and questionnaire research are used with foreign mature scale analysis technique. Employees in manufacturing enterprises are surveyed for data collection. Based on 321 valid questionnaires with correlation analysis and linear regression method, effective data collection is achieved and aimed to explore the relationship among abusive supervision, counterproductive work behavior and negative affectivity of the employees. The results showed: abusive supervision and counterproductive work behavior of employees has a significant positive correlation; negative affectivity of employees is an intermediary variable. The significance of the survey in practice is to encourage leaders of enterprises to improve their strategy of management and pay more attention to the mental health of the employees.
\end{abstract}

\section{Keywords}

Abusive Supervision, Counterproductive Work Behavior, Negative Affectivity, Moderating Effect

\section{Introduction}

In recent years, with the development of the society, people are getting deeper understandings of the concept of management. Researchers devote their effort not only in studying positive aspects of management such as the sense of responsibility and supportive organization, but also in studying negative behaviors like abusive supervision and counterproductive work behavior. Abusive supervision is a common phenomenon in practical enterprise management. Research has shown that abusive supervision such as using insulting words, despite and scorn will negatively affect the mental health of employees [1]. This leads to the decrease of the efficiency and satisfaction level of the employees and the increase of separation rate. In some extreme cases, employees would 
even take retaliatory action to the enterprise. Therefore, studying the relationship among abusive supervision, counterproductive work behavior and negative affectivity has become necessary and significant in improving management strategies and promoting the working attitude of employees.

\section{Theoretical Background and Hypotheses}

\subsection{Concept Definition}

- Abusive Supervision. The term "abusive supervision" is first used by Tepper (2000). It is used to describe hostile behaviors of employers that employees can perceive, including continuous insulting words and behaviors, but excluding physical contact [2]. At present, this definition is still in use. Specific behaviors include humiliating employees, blaming employees to shift responsibility etc. Research has shown that abusive supervision does harm to efficiency of the organization. It is negatively correlated to the satisfaction level of employees, organizational citizenship behavior [3], organizational commitment and voice behavior [4] [5]. Abusive supervision is also positively correlated to the resistance, aggressive behavior and deviant behavior of employees [6].

- Counterproductive Work Behavior. Counterproductive work behavior (CWB) is one of the negative responses of employees to abusive supervision [7]. Typical counterproductive work behavior including intentionally making mistakes, wasting time and money, decreasing productivity, disobeying orders, hindering other colleagues and even stealing from the company. Counterproductive work behavior is defined in many ways by many researchers, including organization attack (Baron \& Neuman, 1996; Neuman \& Baron, 1997; Spector, 1975), audacious behavior (Andersson \& Pearson, 1999), anti-social behavior (Giacalone \& Greenberg, 1997), workplace deviant behaviors (Hollinger, 1986; Robinson \& Bennett, 1995) and vindictive act (Skarlicki \& Folger, 1997) [8].

- Negative Affectivity. Negative affectivity is defined to be emotional situation caused by pressure and unpleasant environment, including anger, aversion, guilt, fear and tension by Watson \& Tellegen (1988). Watson's study has shown that negative affectivity is usually positively correlated to pressure, bad working performance, health problem and unpleasant feelings [9].

\subsection{Research Hypothesis}

- Relationship Between Abusive Supervision and Counterproductive Work Behavior

According to social exchange theory, reciprocity rule is most important in exchange. When employees receive respect, they will repay with higher level of organizational citizenship behavior and organizational commitment [10]. On the contrary, the study of Cropanzano \& Mitchell (2005) has shown that aggressive behavior of employees is likely to be caused by abusive supervision [11]. Because there is a gap between the status and powers of the employees and their managers, tit for tat is not likely to be achieved. The study of Zellars, Tepper, \& Duffy (2002), Tepper (2001) has shown that retaliation of employees will not stop abusive supervision but raise the anger of employers and thus increase the level of abusive supervision [12] Based on this theory, employees tend to choose mild and sneaky ways to retaliate abusive supervision, which is counterproductive work behavior [13]. When employees realized their resistance cannot stop abusive supervision, they tend to take harmful actions to the organization. So we have the following hypothesis:

H1: Abusive supervision has a positive correlation with counterproductive work behavior of employees.

- Relationship Between Negative Affectivity and Counterproductive Work Behavior

Hochschild (1983) has proposed Emotional Labor theory and defined Emotional Labor to be the management of individuals' emotions to create facial expressions and body behaviors that public could acknowledge [14]. The concept has raised great attention in academic world. Although differences exist in definitions, it is commonly approved that emotional labor is the management of emotions in order to fit the organization's expectation.

Hoschild (1983) suggested that emotional labor has three types: Surface, active deep and passive deep. Accordingly, there are three types of affectivities: emotional dissonance, emotional harmony and emotional deviance. Emotional dissonance means the individual emotion fits the standard but do not reflect individual's true feeling. Emotional harmony is individual emotion is truly in the way that the organization expected. Emotional deviance is individuals express their feelings without caring about the organization. When emotional dissonance 
or emotional deviance occurs due to pressure or other factors, negative emotions will accumulate and working efficiency will be affected. In this way, counterproductive work behavior of employees will be caused. So we have the following hypothesis:

H2: Negative affectivity of employees is positively correlated to counterproductive work behavior.

- Moderating Effect of Negative Affectivity

The study of Penny \& Spector (2005) has shown that employees with higher level of negative affectivity is more likely to react to small setback and stimulation, which leads to anger, worry, guilt and frustration [15]. The study of Chen \& Spector (1991), Jex \& Beehr (1991) has pointed out that employees with higher level of negative affectivity are more pessimistic. When encountering pressure, employees with higher level of negative affectivity are more likely to take counterproductive work behavior while employees with lower level of negative affectivity tend to comfort themselves instead of resist. The studies of Aquino (1999), Douglas \& Martinko (2001), Skarlicki (1999) all have shown that counterproductive work behavior is more likely to occur in individuals with higher level of negative affectivity. Thus we can come up with the hypothesis:

H3: Negative affectivity has a moderating effect between abusive supervision and counterproductive work behavior.

\section{Sample and Methods}

\subsection{Sample}

In this research, survey on employees from 4 manufacturing companies is conducted. A mature scale from foreign country is used in the survey, focusing on abusive supervision (15 questions), counterproductive work behavior (33 questions), negative affectivity (10 questions). 400 questionnaires are delivered and 362 (90.5\%) are recycled. $321(80.3 \%)$ of the questionnaires are effective. The demographic characteristics of the sample is shown in Table 1.

\subsection{Scale Reliability and Correlation of Variables}

The scale used in this research is commonly used in foreign studies. It is also proved to be effective in studies taking place in China. The correlation of the variables is analyzed and the Reliability is tested using the scale in this research.

Table 1. Demographic characteristics of the sample.

\begin{tabular}{lcc}
\hline \multicolumn{1}{c}{ Demographic characteristics } & Sample & Percentage \\
\hline Gender & & \\
Male & 145 & $45.2 \%$ \\
Female & 176 & $54.8 \%$ \\
Age & & \\
$\quad \leq 25$ & 65 & $20.2 \%$ \\
26 to 35 & 161 & $50.2 \%$ \\
$\geq 36$ & 95 & $29.6 \%$ \\
Level of education & & \\
Degrees under college & 169 & $52.6 \%$ \\
Bachelor degrees & 139 & $43.3 \%$ \\
Master degrees or above & 13 & $4.1 \%$ \\
Working years & & \\
$\leq 5$ years & 111 & $34.6 \%$ \\
6 - 15 years & 104 & $32.4 \%$ \\
15 - 25 years & 79 & $24.6 \%$ \\
$\geq 26$ years & 27 & $8.4 \%$ \\
\hline
\end{tabular}


- Scale Reliability

The result of reliability test of abusive supervision, counterproductive work behavior and negative affectivity is shown in Table 2.

We can see that the coefficient of internal consistency is more than 0.8 among the 3 variables, which suggests its reliability.

\subsection{Regression Analysis}

- Correlation of Variables

The correlation among Abusive supervision, counterproductive work behavior and negative affectivity is analyzed and the result is shown in Table 3.

In Table 3 we can see the correlation coefficient among abusive supervision, counterproductive work behavior and negative affectivity and reached some conclusions:

Abusive supervision and counterproductive work behavior is positively correlated. The correlation is statistically significant. ( $r=0.396, p<0.01)$. Hypothesis H1 is supported.

Negative affectivity and counterproductive work behavior is positively correlated. The correlation is statistically significant. ( $r=0.396, p<0.01)$. Hypothesis $\mathrm{H} 2$ is supported.

By the analysis above, it is proved that the three variables are correlated; however, the evidence is not enough to confirm the causal relationship. Therefore, regression analysis is used in the following paragraph for further analysis.

- Regression Analysis of Abusive Supervision and Counterproductive Work Behavior

Based on previous analysis, Hierarchical Regression is used to analyze the effect of abusive supervision on counterproductive work behavior. Gender, age, working years and level of education are supposed to affect counterproductive work behavior and considered as control variables. Abusive supervision is considered to be independent variable and counterproductive work behavior is the dependent variable. In the first step we set up a regression model that includes only the dependent variable and control variable, then we add in the dependent variable and get a new model. Comparing the two models, we get Table 4.

In Table 4 we can see that the control variables are not significantly affected by control variables. Only 3.9\% of the difference is explained by control variables. After adding in the dependent variable, the Reliability of the model is significantly improved $\left(\beta=0.000, p<0.001, \Delta \mathrm{R}^{2}=0.151\right)$. The result has proved that hypothesis $\mathrm{H} 1$ is correct.

- The Relationship of Negative Affectivity and Counterproductive Work Behavior

Using the same method of hierarchical regression, we include the control variables in the first step and add negative affectivity as the dependent variable in the second step, we get Table 5 .

As shown in Table 5, controlling demographics variables, negative affectivity significantly increases the accuracy of the model. ( $\left.\beta=0.000, p<0.001, \Delta \mathrm{R}^{2}=0.140\right) \mathrm{H} 2$ is therefore proved.

Table 2. Scale reliability.

\begin{tabular}{cc}
\hline Variables & Cronbach's alpha \\
\hline Abusive supervision & 0.93 \\
Counterproductive work behavior & 0.97 \\
Negative affectivity & 0.92 \\
\hline
\end{tabular}

Table 3. Pearson correlation coefficient $(\mathrm{N}=321)$.

\begin{tabular}{cccc}
\hline Variables & Abusive supervision & Counterproductive work behavior & Negative affectivity \\
\hline Abusive supervision & 1 & 1 & 1 \\
Counterproductive work behavior & $0.396^{* *}$ & $0.379^{* *}$ & 1 \\
Negative affectivity & $0.228^{* *}$ & \\
\hline
\end{tabular}

Notes: ${ }^{* *} p<0.01,{ }^{* * *} p<0.001$. 
Table 4. Regression analysis of abusive supervision and counterproductive work behavior.

\begin{tabular}{ccc}
\hline & \multicolumn{2}{c}{ Dependent variables: Counterproductive work behavior } \\
\cline { 2 - 3 } Variables & Model1 & Model2 \\
\hline Control variable & & 0.117 \\
Sex & 0.110 & 0.136 \\
Age & 0.115 & 0.202 \\
Working years & 0.184 & 0.253 \\
Level of education & 0.309 & $0.000^{* * *}$ \\
Independent variables & & 0.189 \\
Abusive supervision & & 0.164 \\
$\mathrm{R}^{2}$ & 0.039 & $0.151^{* * *}$ \\
Adjusted $\mathrm{R}^{2}$ & 0.015 & $7.573^{* * *}$ \\
$\Delta \mathrm{R}^{2}$ & 0.039 & 1.647 \\
$\mathrm{~F}$ & & \\
\hline
\end{tabular}

Notes: ${ }^{* *} p<0.01,{ }^{* * *} p<0.001, n=321$.

Table 5. Relationship analysis of negative affectivity and counterproductive work behavior.

\begin{tabular}{ccc}
\hline & \multicolumn{2}{c}{ Dependent variables: Counterproductive work behavior } \\
\cline { 2 - 3 } Variables & Model1 & Model12 \\
\hline Control variable & & 0.421 \\
Sex & 0.176 & 0.287 \\
Age & 0.310 & 0.379 \\
Working years & 0.446 & 0.066 \\
Level of education & 0.127 & $0.000^{* * *}$ \\
Independent variables & & 0.174 \\
Negative affectivity & & 0.148 \\
$\mathrm{R}^{2}$ & 0.033 & $0.140^{* * *}$ \\
Adjusted $\mathrm{R}^{2}$ & 0.009 & $6.804^{* * *}$ \\
$\Delta \mathrm{R}^{2}$ & 0.033 & 1.400 \\
$\mathrm{~F}$ & & \\
\hline
\end{tabular}

Notes: ${ }^{* *} p<0.01,{ }^{* * *} p<0.001, n=321$.

- Moderating Effect of Negative Affectivity

To test the moderating effect of negative affectivity between abusive supervision and counterproductive work behavior, we first set up the model including only the control variables: gender, age, working years and level of education. In the second step we include mean-centered coefficient of abusive supervision and counterproductive work behavior. In the third step, the mean-centered interaction variable is also included. The result of the regression analysis is shown in Table 6.

From Table 6 we can see negative affectivity has a moderating effect between abusive supervision and counterproductive work behavior $\left(\beta=0.000, p<0.001, \Delta \mathrm{R}^{2}=0.140, \mathrm{~F}=20.961\right)$. Hypothesis $\mathrm{H} 3$ is proved. 
Table 6. Moderating effect of negative affectivity between abusive supervision and counterproductive work behavior.

\begin{tabular}{|c|c|c|c|}
\hline \multirow{2}{*}{ Variables } & \multicolumn{3}{|c|}{ Dependent variables: Counterproductive work behavior } \\
\hline & Model1 & Model2 & Model3 \\
\hline \multicolumn{4}{|l|}{ Control variable } \\
\hline Sex & 0.165 & 0.377 & 0.089 \\
\hline Age & 0.319 & 0.314 & 0.540 \\
\hline Working years & 0.462 & 0.404 & 0.719 \\
\hline Level of education & 0.133 & 0.060 & 0.054 \\
\hline \multicolumn{4}{|l|}{ Independent variables } \\
\hline Abusive supervision & & $0.000^{* * *}$ & $0.011^{* *}$ \\
\hline \multicolumn{4}{|l|}{ Intervening variables } \\
\hline Negative affectivity & & $0.000^{* * *}$ & $0.001^{* *}$ \\
\hline Abusive supervision $*$ Negative affectivity & & & $0.000^{* * *}$ \\
\hline $\mathrm{R}^{2}$ & 0.033 & 0.262 & 0.480 \\
\hline Adjusted $\mathrm{R}^{2}$ & 0.010 & 0.234 & 0.457 \\
\hline$\Delta \mathrm{R}^{2}$ & 0.033 & $0.229^{* * *}$ & $0.218^{* * *}$ \\
\hline F & 1.400 & $9.465^{* * *}$ & $20.961^{* * *}$ \\
\hline
\end{tabular}

Notes: ${ }^{* *} p<0.01,{ }^{* * *} p<0.001, n=321$.

\section{Results}

In the research, data is analyzed using the scale that has been properly tested. The correlation of abusive supervision, counterproductive work behavior and negative affectivity is computed and tested using regression analysis. The hypothesis is proved. We have reached the following conclusions:

- Abusive supervision has a positive correlation with counterproductive work behavior of employees $(\beta=$ $\left.0.000, p<0.001, \Delta \mathrm{R}^{2}=0.151\right)$.

- Negative affectivity of employees is positively correlated to counterproductive work behavior $(\beta=0.000, p$ $<0.001, \Delta \mathrm{R}^{2}=0.140$ ).

- Negative affectivity has a Moderating Effect between abusive supervision and counterproductive work behavior $\left(\beta=0.000, p<0.001, \Delta \mathrm{R}^{2}=0.140, \mathrm{~F}=20.961\right)$.

The conclusions also proved the previous theory of Fox (2001), Skarlicki (1999), which suggests Negative affectivity has a Moderating Effect between the source of pressure and counterproductive work behavior.

\section{Management Advices}

As Abusive Supervision leads to Negative Affectivity and Counterproductive Work Behavior of employees, it is necessary for managers to take actions to eliminate the negative effects of Abusive supervision in order to prevent loss of the enterprise.

- Pay Attention to the Harm of Abusive Supervision and Improve Management Method. As the research has shown the negative effects of abusive supervision, it is necessary to prevent any harm to the employees with insulting words and attitudes. Building a harmonious and pleasant working environment is helpful in maintaining the efficiency of the enterprise.

- Establishing Rules to Offer Help for the Employees. Enterprises should establish complaint department so that the employees can give feedback about their managers and report abusive supervision in an efficient way. Mental health care of employees should also be included in daily management. Providing necessary psychological counseling services for employees is an efficient way to eliminate the harm that abusive supervision causes to the enterprise.

- Improve Employee Service and Promoting Loyalty. Facing the fierce competition in human resource market, enterprises should take action to enhance mental contract with employees. The employees should share a 
sense of responsibility to the enterprise even in difficult situations. To achieve this goal, human resource managers should improve employee service and care about the emotional feelings of employees. Mental comforting and psychological support should be provided to enable employees to work in a pleasant environment and contribute to the enterprise.

\section{Deficiency of the Research}

- The samples used in the article are from limited areas and only focused on manufacturing industry. The number of samples is also limited. Future research is advised to cover a wider area and collect more data.

- Although the research has shown a strong correlation between abusive supervision and counterproductive work behavior and negative affectivity of employees, the mechanism is still not explained in details and should be noticed in further study.

\section{Acknowledgements}

Supported by Social and Science Planning Fund projects of University of Science \& Technology Liaoning, (2015FR03).

\section{References}

[1] Tepper, B.J. (2007) Abusive Supervision in Work Organizations: Review, Synthesis, and Research Agenda. Journal of Management, 33, 261-289. http://suo.im/9759a http://dx.doi.org/10.1177/0149206307300812

[2] Tepper, B.J. (2000) Consequences of Abusive Supervision. The Academy of Management Journal, 43, 178-190. http://suo.im/ijpn0 http://dx.doi.org/10.2307/1556375

[3] Aryee, S., Sun, L.-Y. and Chen, Z.X.G. (2008) Abusive Supervision and Contextual Performance: The Mediating Role of Emotional Exhaustion and the Moderating Role of Work Unit Structure. Management and Organization Review, 4, 393-411. http://suo.im/oky60 http://dx.doi.org/10.1111/j.1740-8784.2008.00118.x

[4] Yan, D. (2012) The Mechanism and Effect of Abusive Supervision on the Voice Behavior. Journal of Industrial Engineering/Engineering Management, 26, 8-16. http://suo.im/r26cu

[5] Wu, W.K., Wang, W. and Liu, J. (2012) Abusive Supervision, Perceived Psychological Safety and Voice Behavior. Chinese Journal of Management, 9, 57-63. http://suo.im/1wjy1

[6] Zhu, X.M., Lian, X., Hao, L.F. and Ding, T.D. (2015) The Impact of Abusive Supervision on Employees' Counterproductive Work Behavior: The Mediating Role of Emotional Exhaustion. Journal of East China Economic Management, 29, 128-133. http://suo.im/el0jo

[7] Mitchell, M.S. and Ambrose, M.L. (2007) Abusive Supervision and Workplace Deviance and the Moderating Effects of Negative Reciprocity Beliefs. Journal of Applied Psychology, 92, 1159-1168. http://suo.im/wsomi http://dx.doi.org/10.1037/0021-9010.92.4.1159

[8] Zhang, J.W. and Liu, Y.X. (2009) Parsing the Definition and Typology of Enterprise Counterproductive Work Behavior. Advances in Psychological Science, 17, 1059-1066. http://suo.im/upb7i

[9] Zhao, Y., Liu, Y.Z., Chen, G. and Sun, X. (2006) An Empirical Study on Relationships between Positive, Negative Affect and Pay Satisfaction. Science of Science and Management of S. \& T., 7, 152-156.

http://d.g.wanfangdata.com.cn/Periodical kxxykxjsgl200607028.aspx

[10] Masterson, S.S. and Taylor, M.S. (2000) Integrating Justice and Social Exchange: The Differing Effects of Fair Procedures and Treatment on Work Relationships. The Academy of Management Journal, 43, 738-748. http://suo.im/1ve57 http://dx.doi.org/10.2307/1556364

[11] Cropanzano, R. and Mitchell, M.S. (2005) Social Exchange Theory: An Interdisciplinary Review. Journal of Management, 31, 874-900. http://suo.im/3m788 http://dx.doi.org/10.1177/0149206305279602

[12] Zellars, K.L., Tepper, B.J. and Duffy, M.K. (2003) Abusive Supervision and Subordinates’ Organizational Citizenship Behavior. Journal of Applied Psychology, 87, 1068-1076. http://suo.im/61rko http://dx.doi.org/10.1037/0021-9010.87.6.1068

[13] Harris, K.J., Kacmar, K.M. and Zivnuska, S. (2007) An Investigation of Abusive Supervision as a Predictor of Performance and the Meaning of Work as a Moderator of the Relationship. The Leadership Quarterly, 18, 252-263. 
http://suo.im/e8dq4

http://dx.doi.org/10.1016/j.leaqua.2007.03.007

[14] Gregory, B.T., Osmonbekov, T. and Gregory, S.T. (2009) Abusive Supervision and Organizational Citizenship Behaviors: An Examination of Potential Boundary Conditions. Working Paper Series.

http://franke.nau.edu/images/uploads/fcb/09-11.pdf

[15] Penney, L.M. and Spector, P.E. (2005) Job Stress, Incivility, and Counterproductive Work Behavior (CWB): The Moderating Role of Negative Affectivity. Journal of Organizational Behavior, 26, 777-796. http://suo.im/b1e8c http://dx.doi.org/10.1002/job.336 